Article

\title{
Characterization of Emission Factors Concerning Gasoline, LPG, and Diesel Vehicles via Transient Chassis-Dynamometer Tests
}

\author{
Gyutae Park ${ }^{1}$, Sunhee Mun ${ }^{2}$, Heekyoung Hong ${ }^{2}$, Taekho Chung ${ }^{2}$, Sungwoon Jung ${ }^{2}$, \\ Sunmoon Kim ${ }^{2}$, Seokjun Seo ${ }^{2}$, Jounghwa Kim ${ }^{2}$, Jongtae Lee ${ }^{2}$, Kyunghoon Kim ${ }^{1}$, \\ Taehyun Park ${ }^{1}$, Seokwon Kang ${ }^{1}$, Jihee Ban ${ }^{1}$, Dong-Gil Yu ${ }^{1}$, Jung-Hun Woo ${ }^{3}$ and \\ Taehyoung Lee ${ }^{1, *}$ \\ 1 Department of Environmental Science, Hankuk University of Foreign Studies, 81, Oedae-ro, Mohyun-eup, \\ Yongin 17035, Korea; parkgt303@gmail.com (G.P.); khkim159@hufs.ac.kr (K.K.); \\ taehyun_park@naver.com (T.P.); tjrdnjschlrh@naver.com (S.K.); cbjh0822@naver.com (J.B.); \\ envigreen@keiti.re.kr (D.-G.Y.) \\ 2 Transportation Pollution Research Center, National Institute of Environmental Research, 42, Hwangyong-ro, \\ Seogu, Incheon 22689, Korea; sdsg87@korea.kr (S.M.); hong4590@korea.kr (H.H.); cth1990@naver.com (T.C.); \\ actual77@korea.kr (S.J.); ksm432@korea.kr (S.K.); vince007@korea.kr (S.S.); jounghwa@korea.kr (J.K.); \\ leelee@korea.kr (J.L.) \\ 3 Department of Advanced Technology Fusion, Konkuk University, 120, Neungdone-ro, Gwangjin-gu, \\ Seoul 05029, Korea; woojh21@gmail.com \\ * Correspondence: thlee@hufs.ac.kr; Tel.: +82-31-330-4039
}

Received: 16 February 2019; Accepted: 12 April 2019; Published: 16 April 2019

Abstract: Gaseous emissions from vehicles contribute substantially to air pollution and climate change. Vehicular emissions also contain secondary pollutants produced via chemical reactions that occur between the emitted gases and atmospheric air. This study aims at understanding patterns concerning emission of regulated, greenhouse, and precursor gases, which demonstrate potential for secondary aerosol (SA) formation, from vehicles incorporating different engine technologies-multi-point injection (MPI) and gasoline direct injection (GDI) — and using different fuels—gasoline, liquefied petroleum gas (LPG), and diesel. Drive cycles from the National Institute of Environmental Research (NIER) were used in this study. Results obtained from drive cycle tests demonstrate a decline in aggregate gas emissions corresponding to an increase in average vehicle speed. $\mathrm{CO}_{2}$ accounts for more than $99 \%$ of aggregate gaseous emissions. In terms of concentration, $\mathrm{CO}$ and $\mathrm{NH}_{3}$ form predominantly non- $\mathrm{CO}_{2}$ emissions from gasoline and LPG vehicles, whereas nitrogen oxides (NOx) and non-methane hydrocarbons (NMHC) dominate diesel-vehicle emissions. A higher percentage of $\mathrm{SO}_{2}$ is emitted from diesel vehicles compared to their gasoline- and LPG-powered counterparts. EURO-5- and EURO-6-compliant vehicles equipped with diesel particulate filters (DPFs) tend to emit higher amounts of $\mathrm{NO}_{2}$ compared to EURO-3-compliant vehicles, which are not equipped with DPFs. Vehicles incorporating GDI tend to emit less $\mathrm{CO}_{2}$ compared to those incorporating MPI, albeit at the expense of increased $\mathrm{CO}$ emissions. The authors believe that results reported in this paper concerning regulated and unregulated pollutant-emission monitoring can contribute towards an accurate evaluation of both primary and secondary air-pollution scenarios in Korea.

Keywords: precursor gases; greenhouse gases; LPG; diesel; diesel particulate filters (DPFs)

\section{Introduction}

In Korea, regulations concerning gaseous-pollutant emissions from vehicles greatly differ based on the type of fuel used. Gasoline- and LPG-powered vehicles follow emission standards of the United 
States (US), whereas diesel vehicles comply with European emission-control requirements. NOx, CO, and non-methane organic gas (NMOG) emissions are regulated in gasoline- and LPG-powered vehicles, whereas that of particulate matter (PM) is exclusively regulated in vehicles incorporating gasoline direct injection (GDI) combustion technology. In diesel vehicles, however, emissions of NOx, CO, non-methane hydrocarbons (NMHC), PM, and particle number (PN) are all regulated. Furthermore, certain gasoline-, LPG-, and diesel-powered vehicles are subject to additional regulations concerning emission of $\mathrm{NH}_{3}$ and $\mathrm{CH}_{4}$ [1], as described in Table 1.

Table 1. Emission standards in Korea(unit: $\mathrm{g} \mathrm{km}^{-1}$ ).

\begin{tabular}{|c|c|c|c|c|c|c|c|c|}
\hline Regulation & Date & $\mathrm{CO}$ & NOx & $\mathrm{HC}^{\mathrm{a}}$ & HC+NOx & PM & PN & Cycle \\
\hline \multicolumn{9}{|c|}{ Gasoline \& LPG ${ }^{\mathbf{b}}$} \\
\hline ULEV & January 2013 & 1.31 & 0.044 & 0.034 & & $0.004^{\mathrm{c}}$ & & FTP-75 ${ }^{d}$ \\
\hline ULEV & January 2016 & 1.31 & & & 0.078 & 0.004 & & $\begin{array}{c}\text { FTP-75 } \\
\text { US06 }^{\mathrm{e}}, \mathrm{SC} 03^{\mathrm{f}}\end{array}$ \\
\hline \multicolumn{9}{|l|}{ Diesel $\mathrm{g}$} \\
\hline EURO 3 & July 2002 & 1.1 & 0.95 & 0.22 & & 0.11 & & FTP-75 \\
\hline EURO 4 & January 2006 & 0.74 & 0.39 & & 0.46 & 0.06 & & $\mathrm{NEDC}^{\mathrm{h}}$ \\
\hline EURO 5 & September 2009 & 0.74 & 0.28 & & 0.35 & 0.005 & & NEDC \\
\hline EURO 6 & January 2014 & 0.5 & 0.08 & & 0.17 & 0.0045 & $6 \times 10^{11} \mathrm{~km}^{-1}$ & NEDC \\
\hline \multicolumn{9}{|c|}{ 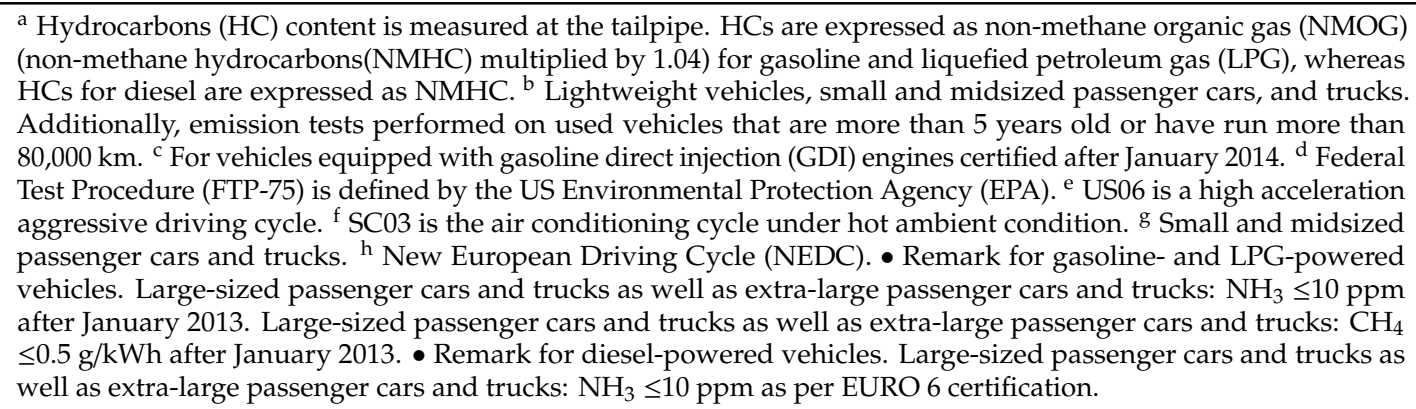 } \\
\hline
\end{tabular}

In addition to regulated pollutants, vehicles emit greenhouse gases (GHG) and precursor gases that tend to form secondary pollutants via atmospheric chemical reactions. $\mathrm{CO}_{2}$-one of the major gases responsible for climate change-accounts for a majority of vehicular emissions. As reported by $\mathrm{O}^{\prime}$ Driscoll et al., $\mathrm{CO}_{2}$ emission from gasoline vehicles when driving in urban areas increases by $13-66 \%$ compared to that from EURO-5- and EURO-6-compliant diesel vehicles equipped with a portable emission-measurement system (PEMS) [2]. Although recent researches demonstrate that direct $\mathrm{NO}_{2}$ emissions from newer diesel vehicles have been decreased substantially through a more stringent EURO standard, it still constitutes the main reason behind affecting ambient- $\mathrm{NO}_{2}$ concentration at roadside locations because of high NOx-emitter diesel vehicles between EURO 3 and EURO 5 standards $[3,4]$ and the fact that $\mathrm{NO}$ emissions of some large diesel vehicles have not been decreasing as expected $[5,6]$.

In recent years, the public has become increasingly aware of the production of secondary pollutants via reactions between primary pollutants and other chemicals. In urban areas, vehicular emissions have been found to be a dominant source of gaseous pollutants [7]. Using an oxidation detector inside a confined space, Link et al. investigated secondary-pollutant formation by measuring the production of secondary inorganic aerosols (SIA) from vehicle-emitted $\mathrm{NOx}$ and $\mathrm{NH}_{3}$ gases [8]. In metropolitan cities, SIA production can be largely attributed to vehicular emissions. Gordon et al. reported that speciated and unspeciated NMOGs contribute towards the formation of secondary organic aerosols (SOA) and that nearly $30 \%$ of all NMOGs produced from gasoline in newer vehicles cannot be speciated [9].

Gaseous emissions also result in a variety of environmental issues, including ground-level pollution, climate change (caused by GHGs), and secondary-pollutant formation. Researches concerning gaseous 
emissions must, therefore, be more comprehensive instead of focusing exclusively on pollutant emissions. To address this concern, the proposed study measures and analyzes emission trends concerning a wide range of regulated gaseous pollutants, greenhouse gases, and particle-precursor gases released from vehicles fueled with gasoline, LPG, and diesel. Further, gasoline vehicles have been classified based on the engine technology (GDI or multi-point injection (MPI)) incorporated therein, whereas diesel vehicles have been classified based on European emission-regulation standards—namely EURO 3, EURO 5, and EURO 6.

\section{Methods}

\subsection{Vehicle-Selection Criteria and Test Cycle}

Table 2 lists the specifications of the vehicles used in this study. High-market-share vehicles were preferentially selected-using data provided by the Transportation Pollution Research Center in the National Institute of Environmental Research (NIER)—and vehicles with similar engine displacements were considered for minimizing differences between emission patterns. To investigate differences between pollutant-emission patterns corresponding to different engine types, gasoline-powered vehicles considered in this study included those incorporating MPI technology, wherein fuel is anteriorly dispersed to the cylinder intake valve, and GDI technology, wherein fuel is directly injected into the cylinder [10]. Vehicles incorporating GDI technology were further classified as preand post-PM-emission-regulation vehicles depending on whether they were manufactured prior to or after 2014 (when PM-emission regulations were first imposed on GDI-incorporated vehicles), respectively. PM-emission regulations concerning GDI vehicles influence the combustion technology employed during engine operation. This, in turn, affects the composition of exhaust gases emitted by GDI-incorporated vehicles via hardware and software control to satisfy PM regulation requirements. As already mentioned, diesel vehicles considered in this study were classified in accordance with relevant pollutant-emission regulations, such as the EURO 6 (current regulations), EURO 5 (previous regulations), and EURO 3-which includes vehicles without diesel particulate filters (DPFs) to account for the pollution contribution of older vehicles. EURO-6 compliant vehicles feature three preinstalled after-treatment devices-DPFs, diesel oxidation catalyst (DOCs), and lean NOx traps (LNTs). Accordingly, EURO-5-compliant vehicles are equipped with DOCs and DPFs, whereas EURO-3-compliant ones exclusively feature DOCs.

Table 2. Specifications of vehicles considered in this study.

\begin{tabular}{|c|c|c|c|c|c|c|c|c|c|}
\hline No. & ID $^{a}$ & Type & Fuel & Year & Displacement (cc) & Engine & Mileage (km) & $\begin{array}{c}\text { After-Treatment } \\
\text { Device }\end{array}$ & $\begin{array}{l}\text { Emission } \\
\text { Standard }\end{array}$ \\
\hline 1 & G1 & Passenger & Gasoline & 2015 & 1999 & $\mathrm{MPI}^{\mathrm{b}}$ & 44,238 & TWC $^{\mathrm{c}}$ & ULEV \\
\hline 2 & $\mathrm{G} 2$ & Passenger & Gasoline & 2015 & 2999 & GDI $^{d}$ & 69,057 & TWC & ULEV \\
\hline 3 & G3 & Passenger & Gasoline & 2016 & 1591 & GDI & 25,944 & TWC & ULEV \\
\hline 4 & G4 & Passenger & Gasoline & 2015 & 1591 & GDI & 24,570 & TWC & ULEV \\
\hline 5 & L1 & Passenger & LPG & 2014 & 2999 & $\mathrm{LPI}^{\mathrm{e}}$ & 87,606 & TWC & ULEV \\
\hline 6 & L2 & Passenger & LPG & 2015 & 1519 & LPI & 142,492 & TWC & ULEV \\
\hline 7 & L3 & Passenger & LPG & 2015 & 2999 & LPI & 70,324 & TWC & ULEV \\
\hline 8 & D1 & Truck & Diesel & 2016 & 2497 & $D I^{f}$ & 11,239 & $\mathrm{DOC}^{\mathrm{g}}, \mathrm{DPF}^{\mathrm{h}}$ & EURO 5 \\
\hline 9 & D2 & Passenger & Diesel & 2016 & 2199 & DI & 15,606 & DOC, DPF, LNT ${ }^{\mathrm{i}}$ & EURO 6 \\
\hline 10 & D3 & Passenger & Diesel & 2016 & 1582 & DI & 37,018 & DOC, DPF, LNT & EURO 6 \\
\hline 11 & D4 & SUV & Diesel & 2002 & 1991 & DI & 183,472 & DOC & EURO 3 \\
\hline
\end{tabular}

a Vehicle IDs beginning with G, D, and L indicate gasoline, diesel, and LPG fueling, respectively; ${ }^{\mathrm{b}}$ MPI: Multi Port Injection; ${ }^{\mathrm{c}}$ TWC: Three-way Catalyst; ${ }^{\mathrm{d}}$ GDI: Gasoline Direct Injection; ${ }^{\mathrm{e}}$ LPI: Liquid Phase Injection; ${ }^{\mathrm{f}}$ DI: Direct Injection; ${ }^{g}$ DOC: Diesel Oxidation Catalyst; ${ }^{\mathrm{h}}$ DPF: Diesel Particulate Filter; ${ }^{\mathrm{i}}$ LNT: Lean NOx Trap.

All vehicles were run on a chassis dynamometer in accordance with NIER drive cycle test procedures followed in Korea to measure emissions of GHGs, regulated gases, and SA precursors. The NIER drive cycles have been developed based on Korean road-traffic patterns and comprise 15 different cycles based on the average vehicle speed (from low to high). Drive cycles considered in this study included NIER-01 (average speed: $4.7 \mathrm{~km} \mathrm{~h}^{-1}$ ), NIER-05 (average speed: $17.3 \mathrm{~km} \mathrm{~h}^{-1}$ ), 
NIER-09 (average speed: $34.1 \mathrm{~km} \mathrm{~h}^{-1}$ ), and NIER-12 (average speed: $65.4 \mathrm{~km} \mathrm{~h}^{-1}$ ) to assess driving conditions within metropolitan cities (Figure 1 and Table 3). Emission measurements during selected chassis-dynamometer tests were performed at ambient temperatures in the range of $20-27^{\circ} \mathrm{C}$ and relative humidity of the order of $40-45 \%$ to minimize the effect of variations in the surrounding environment on emissions. Prior to performing measurements, the condition of each test vehicle was evaluated using an On-board Diagnostics (OBD) scanner. Diesel vehicles were evaluated for PM loading within DPFs to assess the need for regeneration. If regeneration was deemed necessary, the same was artificially induced, and gaseous species and particulate matter analyzers were employed to confirm complete regeneration.
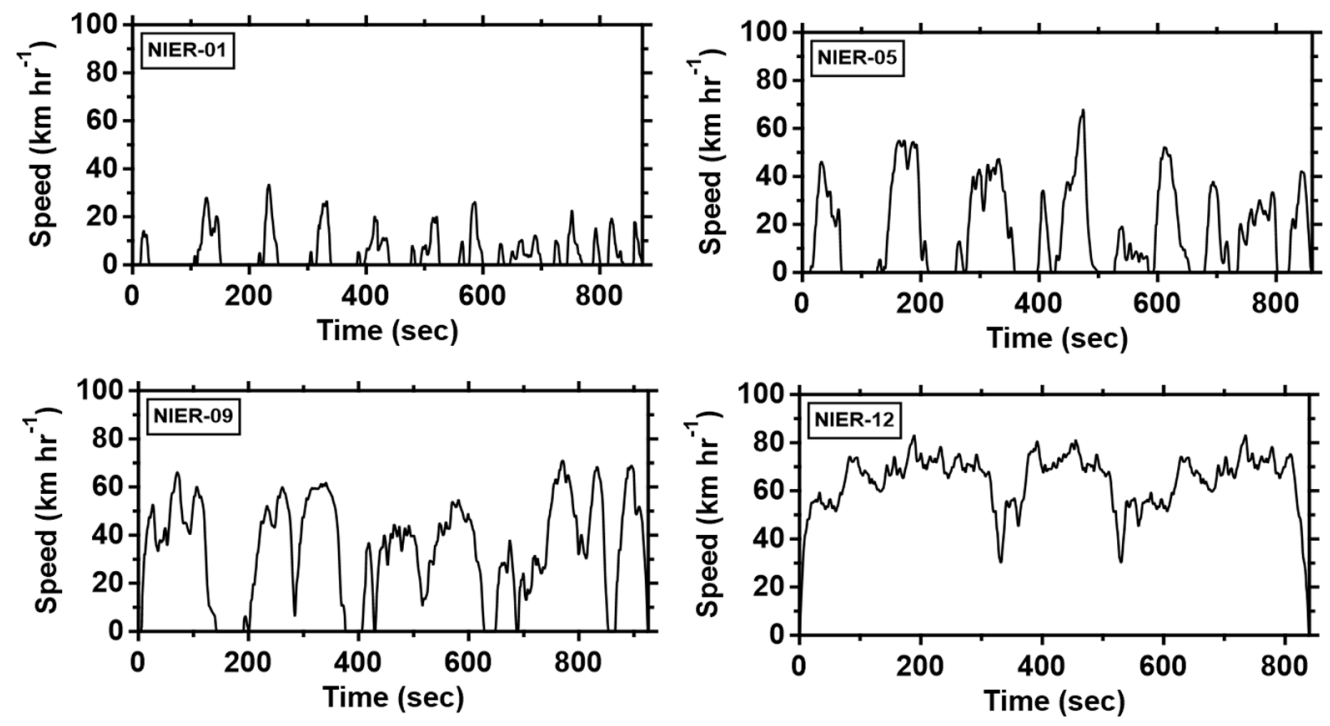

Figure 1. Speed profiles concerning test cycles considered in this study.

Table 3. Specifications of test cycles considered in this study.

\begin{tabular}{|c|c|c|c|c|}
\hline Cycle & Total Duration (s) & Distance (km) & Average Speed $\left(\mathrm{km} \mathrm{h}^{-1}\right)$ & Maximum Speed $\left(\mathrm{km} \mathrm{h}^{-1}\right)$ \\
\hline NIER $^{\mathrm{a}}-01$ & 873 & 1.1 & 4.7 & 33.4 \\
\hline NIER-05 & 864 & 4.2 & 17.3 & 68.1 \\
\hline NIER-09 & 926 & 8.8 & 34.1 & 70.9 \\
\hline NIER-12 & 840 & 15.3 & 65.4 & 83.3 \\
\hline
\end{tabular}

a NIER: National Institute of Environmental Research.

\subsection{Gaseous-Component Analysis}

During chassis-dynamometer tests, exhaust gases from test-vehicle tailpipes were directly sampled using a constant-volume sampler (CVS) tunnel (CVS flow rate: $20 \mathrm{~m}^{3} \mathrm{~min}^{-1}$ ). Gases collected within the CVS tunnel were diluted by the factor of $\sim 10-95$ using purified dilution air treated by activated carbon and passed through a high-efficiency particle (HEPA) filter. Subsequently, diluted gases within the CVS tunnel were drawn into Tedlar bags, and gas samples were analyzed to determine average concentrations of target pollutant gas species through use of a flame ionization detection analyzer (HORIBA; FIA-720) for total hydrocarbons (THCs), chemiluminescence detection analyzer (HORIBA; CLA-720A) for NOx, non-dispersive infrared analyzer (HORIBA; AIA-721A and AIA-722) for CO and $\mathrm{CO}_{2}$, and gas chromatography flame ionization detection analyzer (HORIBA; GFA-720) for $\mathrm{CH}_{4}$. NMHC concentration within exhaust gases sampled from diesel-powered vehicles was defined as THC minus $\mathrm{CH}_{4}$, whereas NMOG content within gases sampled from gasoline- and LPG-powered vehicles was defined as 1.04 times the NMHC concentration [1]. After removal of hydrocarbons from gas samples collected from the CVS tunnel, $\mathrm{SO}_{2}$ concentration within the remaining gas was measured using a pulsed fluorescence detection analyzer (Thermo Scientific; $43 \mathrm{C}$ ). $\mathrm{NH}_{3}, \mathrm{NO}$, and $\mathrm{NO}_{2}$ 
concentrations were monitored via quantum cascade laser spectroscopy (HORIBA; MEXA-1400QL-NX). $\mathrm{NH}_{3}$ was directly extracted from the tailpipe using heated tubing $\left(\right.$ at $115^{\circ} \mathrm{C}$ ). This is because gaseous $\mathrm{NH}_{3}$ demonstrates strong adsorption on the walls of the dilution tunnel, thereby inducing errors in measurement of its actual concentration. Measurements concerning $\mathrm{NO}$ and $\mathrm{NO}_{2}$ concentrations within exhaust gas samples were also similarly performed to determine the ratio of $\mathrm{NO}_{2}$ to $\mathrm{NOx}$ within undiluted vehicle exhaust. Emission rate from CVS tunnel was quantified using Equation (1):

$$
\text { Emission rate, } \mathrm{g} \mathrm{km}^{-1} \text { from CVS tunnel }=\frac{\mathrm{V}_{\text {mix }} \times \rho_{\mathrm{i}} \times \mathrm{C}_{\mathrm{i}(\text { corrected })}}{\mathrm{d}}
$$

where $V_{\text {mix }}$ is total volume $\left(\mathrm{m}^{3}\right)$ in the CVS tunnel during durations of running cycle, $\rho_{\mathrm{i}}$ is the density of gases $\left(\mathrm{kg} \mathrm{m}^{-3}\right)$, and $\mathrm{C}_{\mathrm{i}(\text { corrected })}$ is the concentration of exhaust gases which is corrected for the CVS tunnel background. $\mathrm{d}$ is the total driving distance $(\mathrm{km})$ of each cycle. The direct emission rate was calculated using the following Equation (2):

$$
\text { Emission rate, } \mathrm{g} \mathrm{km}^{-1} \text { from direct measurement }=\frac{\mathrm{C}_{\mathrm{i}(\text { corrected })} \times \rho_{\mathrm{i}} \times \text { flow }_{(\text {cvs tunnel })}}{\operatorname{Speed}_{(\mathrm{avg})} \times \mathrm{DF}}
$$

where $C_{i(\text { corrected) }}$ is the concentration which is corrected by the instrument blank periodically, flow $_{(\text {cvs tunnel) }}$ is the CVS flow rate $\left(\mathrm{m}^{3} \mathrm{~min}^{-1}\right)$ during cycles. Speed $\left(\right.$ avg) is the average speed $\left(\mathrm{km} \mathrm{h}^{-1}\right)$ of each cycle, and DF is the dilution factor reported from the measurement of the CVS tunnel system.

\section{Results and Discussion}

\subsection{Characteristics of Gaseous Emissions from Vehicles Powered by Different Fuel Types}

Results obtained from chassis dynamometer tests performed as described in the previous section are depicted in Figure 2. A non-DPF-equipped diesel vehicle manufactured prior to the adoption of strengthened pollutant-emission regulations (and hence, considered old) was observed to emit higher concentrations of gaseous pollutants compared to modern vehicles. Except for NOx emissions from gasoline- and LPG-powered vehicles, the aggregate pollutant emission was observed to decline corresponding to an increase in average vehicle speed. The observed high emission volume during the NIER-01 drive cycle indicates that the functional behavior of after-treatment systems could not be realized until attainment of an appropriate working temperature to facilitate sufficient purification of gas emissions during low-speed operation [11,12].

Investigation of $\mathrm{NH}_{3}$ emission from vehicles is important from the viewpoint of estimating ambient air pollution in urban areas because gaseous $\mathrm{NH}_{3}$ can act as a precursor, thereby facilitating SIA production via chemical reactions with NOx and SOx [13]. Figure $2 \mathrm{f}$ depicts the observed trends concerning $\mathrm{NH}_{3}$ emission during chassis-dynamometer tests performed at different average speeds. In gasoline- and LPG-powered vehicles, $\mathrm{NH}_{3}$ emission declines with an increase in average vehicle speed. The corresponding relationship can, therefore, be expressed in terms of an emission factor for calculating the total emission of on-road vehicles. Diesel vehicles, in general, emit low amounts of $\mathrm{NH}_{3}$. That said, diesel vehicles equipped with a urea-based selective catalytic reduction (SCR) system tend to encounter a problem referred to as "ammonia slip" emission [14]. Emissions from such vehicles, however, were not investigated in this study. At present, in Korea, $\mathrm{NH}_{3}$ emissions from large and extra-large passenger cars and trucks are regulated to values not exceeding $10 \mathrm{ppm}$ using the engine driving test [1]. Although results obtained from chassis-dynamometer tests would, in general, differ from those obtained under actual on-road conditions, findings of this study, nonetheless, demonstrate that $\mathrm{NH}_{3}$ emissions are possible from small- and medium-sized vehicles. Further investigations must be undertaken to determine which vehicles must be subject to additional regulations to prevent the formation of secondary pollutants due to $\mathrm{NH}_{3}$ emission. 

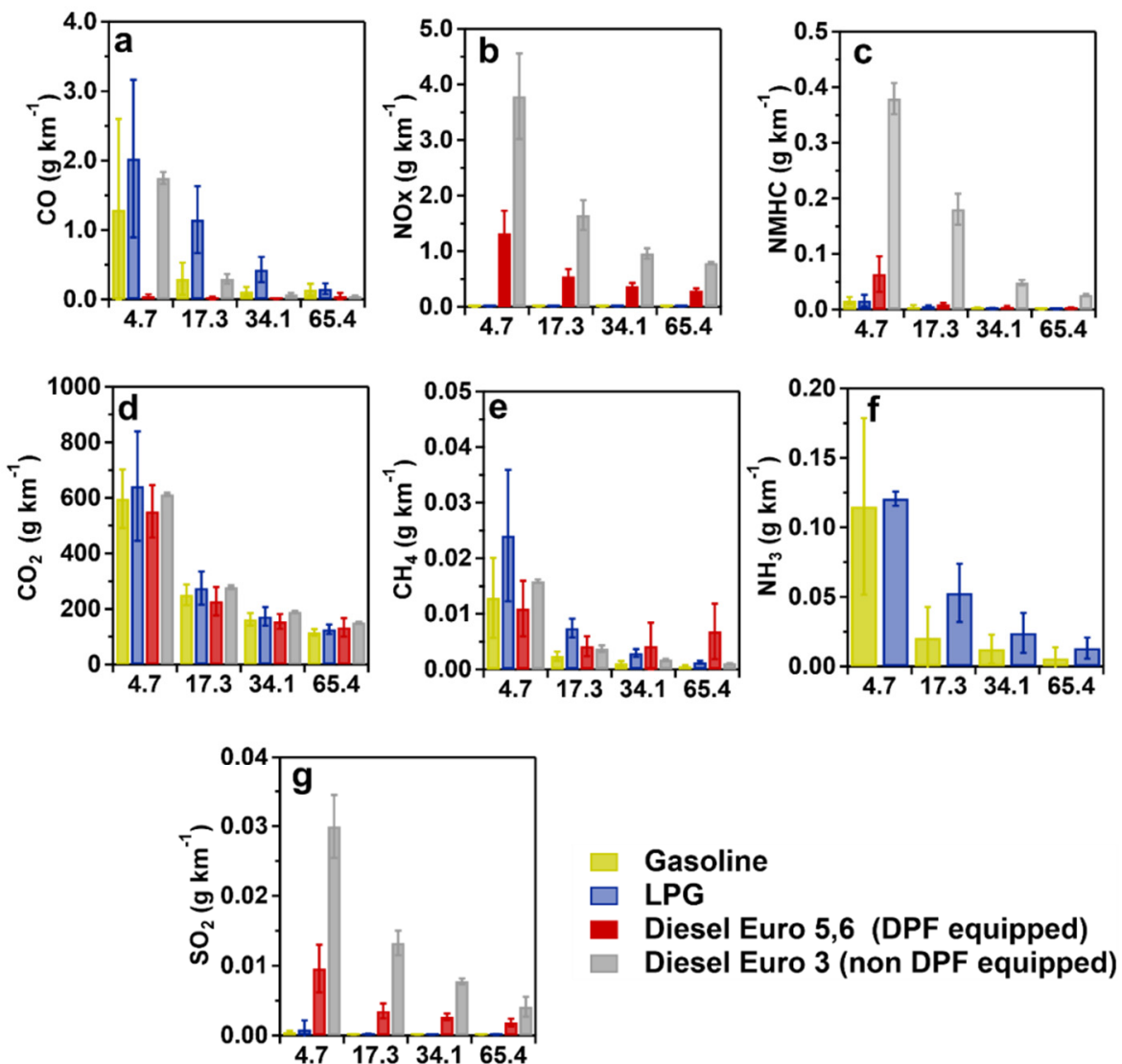

Average Speed $\left(\mathrm{km} \mathrm{hr}^{-1}\right)$

Figure 2. Trends concerning emission rates of (a) $\mathrm{CO},(\mathbf{b}) \mathrm{NOx}$, (c) $\mathrm{NMHC}$, (d) $\mathrm{CO}_{2},(\mathbf{e}) \mathrm{CH}_{4},(\mathbf{f}) \mathrm{NH}_{3}$, and $(\mathrm{g}) \mathrm{SO}_{2}$ measured during the National Institute of Environmental Research (NIER) cycle tests performed on vehicles powered by different fuels.

Emission of sulfur oxides $\left(\mathrm{SO}_{2}, \mathrm{SO}_{3}\right.$, and $\left.\mathrm{H}_{2} \mathrm{SO}_{4}\right)$ from vehicles is, in general, detrimental to the durability of catalyst devices. Additionally, sulfur oxides react with atmospheric $\mathrm{NH}_{3}$ to produce ammonium sulfate $\left(\left(\mathrm{NH}_{4}\right)_{2} \mathrm{SO}_{4}\right)$-a secondary pollutant [15]. Most sulfur oxides are produced by the reaction of sulfur present within fuel with oxygen during combustion of fuel-air mixtures within automotive engines. Additionally, a recent study has revealed the conversion of $\mathrm{SO}_{2}$ to $\mathrm{SO}_{3}$ within high-temperature after-treatment devices [16]. In Korea, regulations concerning chemical composition of fuels mandate less than $10 \mathrm{ppm}$ of sulfur within gasoline and diesel; the corresponding regulation for LPG mandates less than $40 \mathrm{ppm}$ of sulfur. However, studies concerning actual sulfur-oxide emissions are relatively rare. Figure $2 \mathrm{~g}$ depicts trends concerning $\mathrm{SO}_{2}$ emissions when using different fuel types. As observed, $\mathrm{SO}_{2}$-emission rates vary in the range of $0.0001-0.0005 \mathrm{~g} \mathrm{~km}^{-1}$ for gasoline vehicles, $0.0001-0.0009 \mathrm{~g} \mathrm{~km}^{-1}$ for LPG vehicles, $0.0019-0.0096 \mathrm{~g} \mathrm{~km}^{-1}$ for diesel vehicles, and 0.0041-0.03 $\mathrm{g}$ $\mathrm{km}^{-1}$ for diesel vehicles without DPF. The high emission rates in diesel vehicles can be attributed to the fact that diesel combustion requires higher air pressures (i.e., greater compression within the engine), which in turn, further enhances the probability of chemical reactions occurring between sulfur and oxygen.

Figure $3 a$ depicts the average pollutant-emission rates calculated during different chassis-dynamometer tests performed in this study. As can be observed, for all fuel types, $\mathrm{CO}_{2}-\mathrm{a}$ greenhouse gas-constitutes more than $99 \%$ of aggregate emissions, whereas CO constitutes $89 \%$ and 92.7\% of all non- $\mathrm{CO}_{2}$ gas species emitted from gasoline- and LPG-powered vehicles, respectively. Corresponding mass fractions for $\mathrm{NH}_{3}$ were $7.6 \%$ and $4.7 \%$, respectively, for gasoline- and LPG-powered vehicles, whereas those for other gases were measured by less than $1 \%$. On the other hand, mass fractions 
of emitted NOx species equal $91.2 \%$ and $71.9 \%$ in diesel vehicles with and without DPF, respectively. Corresponding mass fractions of CO and NMHC in DPF equipped diesel vehicles are $4.2 \%$ and 3\%, respectively. Diesel vehicle without DPF emits a significant amount of NOx while also featuring relatively high $\mathrm{CO}$ and NMHC mass fractions $(20.8 \%$ and $6.5 \%$, respectively). This implies that non-DPF-equipped diesel vehicles release more complex air pollutants compared to vehicles powered by other fuel types. These results demonstrate the importance of classifying test vehicles based on fuel type with regard to calculating the amount of air pollution caused by different fuels. The results also facilitate the imposition of customized regulations on the use of specific fuel types. Most importantly, such regulations would help restrict both the emission of primary pollutants and potential formation of secondary pollutants within the atmosphere. Further investigations in this regard must, therefore, be undertaken.

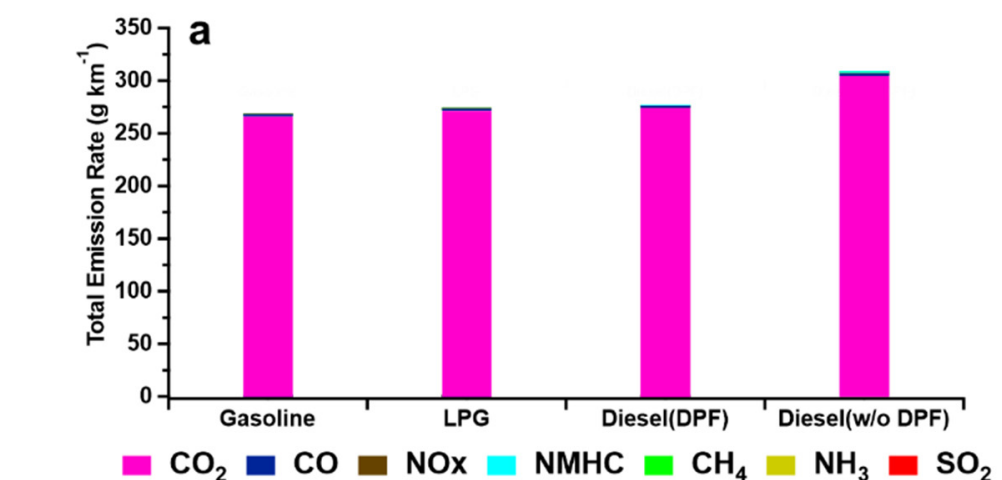

\section{b}

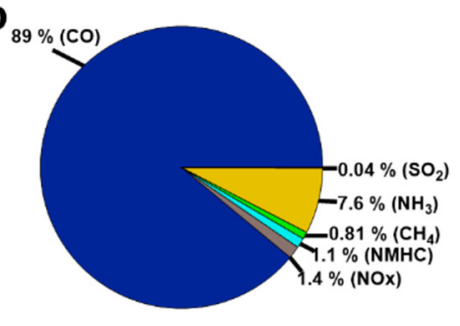

Gasoline

Mass : $0.47 \mathrm{~g} \mathrm{~km}^{-1}$$$
\text { d }
$$

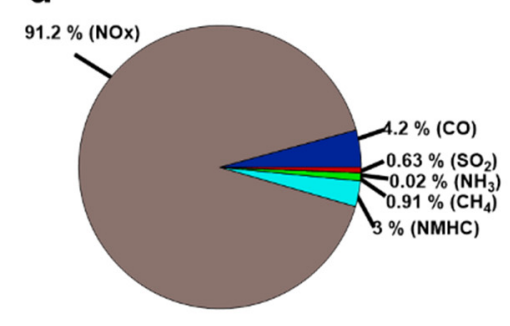

Diesel Euro 5,6 (DPF equipped) Mass : $0.72 \mathrm{~g} \mathrm{~km}^{-1}$

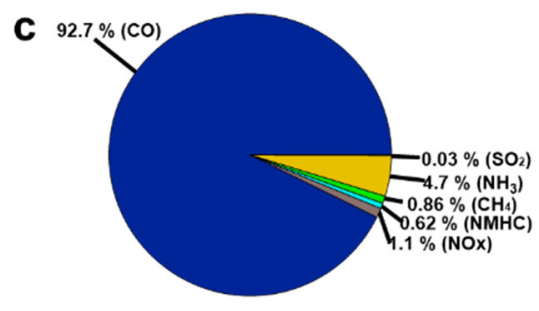

LPG

Mass : $0.88 \mathrm{~g} \mathrm{~km}^{-1}$

e

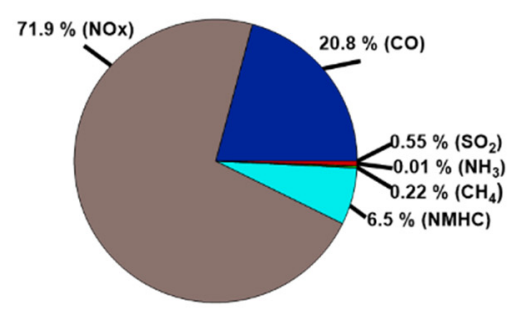

Diesel Euro 3 (non DPF equipped) Mass : $2.5 \mathrm{gkm}^{-1}$

Figure 3. (a) Rates of $\mathrm{CO}_{2}$ emission of gases constituting different fuels. Mass fractions all gases except $\mathrm{CO}_{2}$ in (b) gasoline, (c) liquefied petroleum gas (LPG), (d) diesel particulate filter (DPF)-equipped diesel, and (e) non-DPF-equipped diesel. All values correspond to total averages calculated during NIER chassis-dynamometer tests

\subsection{Emissions Caused by Use of Different Gasoline-Combustion Technologies}

Two types of combustion technologies-MPI and GDI-exist for use in gasoline vehicles. GDI-based vehicles benefit from enhanced fuel efficiency and reduced $\mathrm{CO}_{2}$ generation compared to 
their MPI-based counterparts. However, GDI-based vehicles emit higher amounts of PM compared to those incorporating MPI owing to their inherent incomplete combustion and droplet wall wetting of cylinder surfaces [17]. In 2014, the Korean government imposed regulations on PM emissions from gasoline with GDI engine- and diesel-powered vehicles (previously, only diesel-powered vehicles were regulated). For gasoline-powered vehicles equipped with GDI engines, the specified PM-emission limit was set to $0.004 \mathrm{~g} \mathrm{~km}^{-1}$ [1]. This change in emission regulations led to a change in the composition of exhaust gases emitted from the latest gasoline-powered vehicles. Figure 4 depicts observed emission trends from gasoline-powered vehicles equipped with different combustion systems-MPI, GDI 1 (before PM regulations), and GDI 2 (after PM regulations). As observed and previously discussed, total pollutant emissions were observed to decrease corresponding to an increase in average vehicle speed. Additionally, emission rates of gases other than $\mathrm{CO}_{2}$ demonstrated a decrease with increasing vehicle speed up to a certain point; this was followed by a subsequent increase thereafter. $\mathrm{CO}$ accounted for the majority of non- $\mathrm{CO}_{2}$ emissions. Vehicles incorporating MPI and GDI 2 technologies demonstrated emissions with $\mathrm{NH}_{3}$ mass fractions in the range of $2-28 \%$ of all non- $\mathrm{CO}_{2}$ pollutants across all chassis-dynamometer tests. In contrast, GDI-1-equipped vehicles demonstrated very low $\mathrm{NH}_{3}$ emissions (mass fraction of approximately $0.3 \%$ of all non- $\mathrm{CO}_{2}$ emissions). Given that $\mathrm{NH}_{3}$ is produced via reactions involving $\mathrm{CO}, \mathrm{H}_{2} \mathrm{O}$, and $\mathrm{NO}$ inside TWCs [18] its emission rate depends on the vehicle's combustion-system type, after-treatment device technology, driving patterns, and vehicle manufacturer strategy towards emission control.

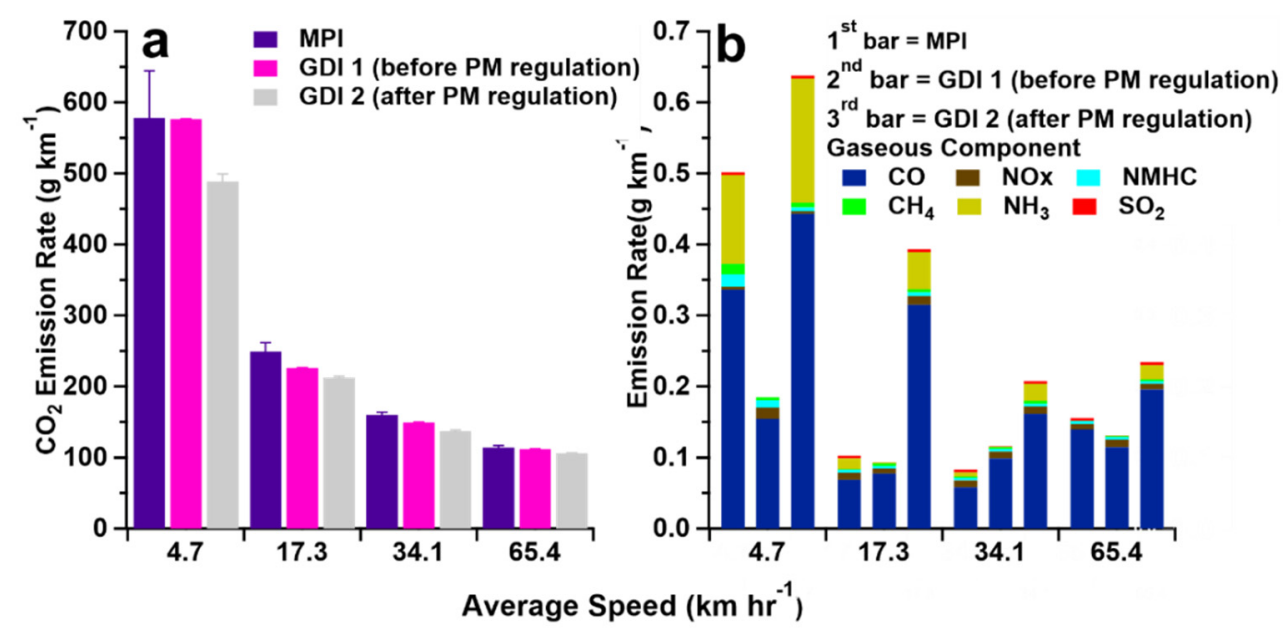

Figure 4. Results obtained from chassis dynamometer tests performed on gasoline vehicles incorporating different combustion technologies and operating at different speeds-(a) Trends concerning $\mathrm{CO}_{2}$-emission rate; (b) Trends concerning emission rates of $\mathrm{CO}, \mathrm{NOx}$, non-methane hydrocarbons (NMHC), $\mathrm{CH}_{4}, \mathrm{NH}_{3}$, and $\mathrm{SO}_{2}$

\subsection{Emissions from Diesel-Powered Vehicles under Different Emission Regulations}

NOx emissions from diesel-powered engines mostly occur in the form of NO, a portion of which gets further oxidized to form $\mathrm{NO}_{2}$ within DOCs prior to emission from the tailpipe [19]. Figure 5 depicts emission trends concerning diesel vehicles during the NIER drive-cycle performed in accordance with different emission regulations imposed over time. As can be observed, with the exception of a few measurements, the proportion of $\mathrm{NO}_{2}$ within $\mathrm{NOx}$ emissions increases with an increase in vehicle speed. However, the magnitudes of these increases are relatively small. In EURO-3-compliant vehicles, $\mathrm{NO}_{2}$ accounts for only $1-3 \%$ of the total NOx emissions. As regard EURO-6- and EURO-5-compliant vehicles, the corresponding proportions of $\mathrm{NO}_{2}$ within NOx emissions lie in the range of $12-16 \%$ and $21-28 \%$, respectively. This trend is similar to that reported in extant studies $[3,20,21]$, thereby illustrating the conversion of $\mathrm{NO}$ to $\mathrm{NO}_{2}$ in the presence of a catalyst and high-temperature conditions within after-treatment components. 


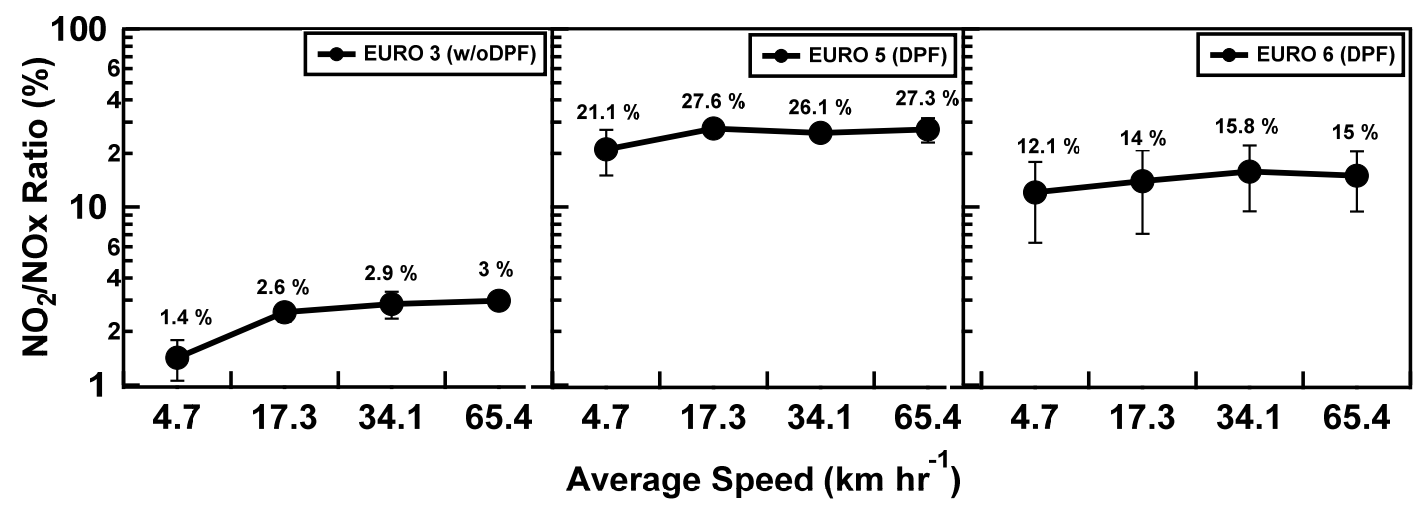

Figure 5. Observed trends in the variation of $\mathrm{NO}_{2} / \mathrm{NOx}$ ratio and standard deviation concerning emissions from diesel vehicles as per different emission-regulation standards for different diesel-vehicle speeds.

EURO-6-compliant emission regulations on diesel vehicles are currently in effect in Korea. EURO 6 features stricter regulations on NOx and PM emissions compared to EURO [1]. Emissions from diesel vehicles manufactured in accordance with a given regulation standard are controlled via the use of improved combustion technology and after-treatment devices. Figure $6 \mathrm{~b}$ depicts proportions of regulated, unregulated, and GHG gases within the non- $\mathrm{CO}_{2}$ emissions from diesel-powered vehicles. $\mathrm{CO}_{2}$ emissions from EURO-6-compliant vehicles can be observed to be lower as a result of mixed displacement. NOx, CO, and NMHC are dominant gas species emitted by EURO-3-compliant vehicles without DPFs. NOx constitutes $89 \%$ of the total non- $\mathrm{CO}_{2}$ emissions from EURO-5- and EURO-6-compliant vehicles. Although emitted concentrations of gas species other than $\mathrm{CO}_{2}$ have, over the years, been reduced owing to strengthened regulations, the proportions of NOx emitted from diesel-powered vehicles has remained relatively high. Increased concentration of NOx gases in the atmosphere may result in the production of hazardous $\mathrm{O}_{3}$ gas in combination with VOCs (Volatile Organic Compounds) [22,23]. Furthermore, NOx gases serve as precursor species that react with PMs and other gas species to produce secondary aerosols. Therefore, diesel vehicles that emit large amounts of NOx gases must be regulated to counter the adverse effects on human health as well as atmospheric pollution.

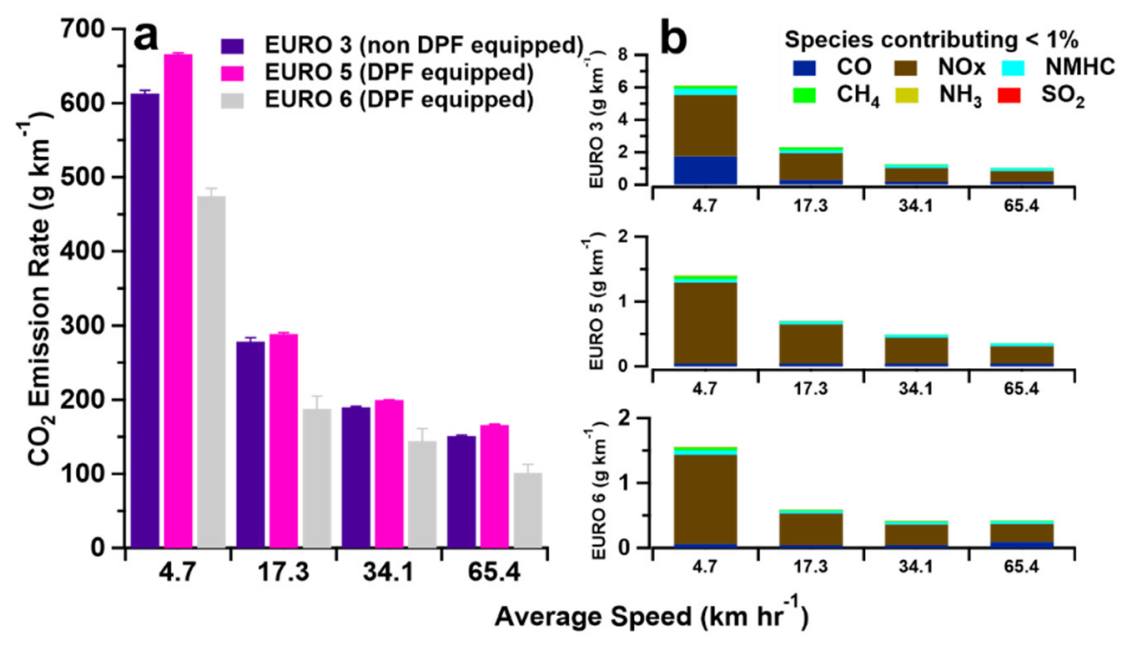

Figure 6. Results obtained from chassis-dynamometer tests performed on diesel vehicles complying with different emission-regulation standards and operating at different speeds. (a) Trends concerning $\mathrm{CO}_{2}$-emission rates; (b) Trends concerning emission rates of $\mathrm{CO}, \mathrm{NOx}, \mathrm{NMHC}, \mathrm{CH}_{4}, \mathrm{NH}_{3}$, and $\mathrm{SO}_{2}$ gases. 


\section{Conclusions}

This study was performed to investigate and understand the emission patterns of different automotive engines and fuel types used in Korea. Vehicles considered in this study were classified based on their type, the fuel-injection/combustion technology employed, and the emission-regulation standards complied with. Vehicular emissions were detected in real time under conditions of varying average speeds of vehicles. The conclusions drawn from this study can be summarized as follows:

(1) Emissions of all gaseous pollutants demonstrated an initial decrease with an increase in average speed. For all vehicle types, $\mathrm{CO}_{2}$ accounted for more than $99 \%$ of aggregate emissions, whereas the remaining $1 \%$ was comprised of various gas species, and its composition varied depending on the type of fuel used.

(2) $\mathrm{CO}$ and $\mathrm{NH}_{3}$ were observed to be predominant non- $\mathrm{CO}_{2}$ species of pollutants emitted from gasoline- and LPG-powered vehicles, whereas emissions from diesel-powered vehicles were dominated by $\mathrm{NOx}, \mathrm{CO}$, and NMHC. Additionally, $\mathrm{SO}_{2}$ emissions from diesel-powered vehicles were observed to exceed those from their gasoline- and LPG-powered counterparts by up to 28 times.

(3) Strengthening emission-regulation standards for diesel vehicles has somewhat reduced the effect of NOx emissions in recent years. However, the value of the $\mathrm{NO}_{2} / \mathrm{NO}$ ratio has witnessed a significant increase, as depicted in Figure 5, owing to advancement in combustion technology and operating conditions of after-treatment devices.

(4) Gaseous pollutants, such as $\mathrm{NOx}, \mathrm{NMHC}, \mathrm{NH}_{3}$, and $\mathrm{SO}_{2}$, emitted by vehicles employing different types of fuel constitute a major source of primary pollution, and these tend to ultimately react with other atmospheric species to produce secondary gases and PM. Inhibition of potential atmospheric pollution, therefore, requires the development of stringent regulations and establishment of emission-reduction policies.

Author Contributions: Conceptualization, G.P. and T.L.; methodology, G.P., K.K., T.L.; installation vehicles on chassis dynamometer, G.P., K.K., S.M., H.H., T.C., S.K., J.B.; formal analysis, G.P., K.K., S.K., T.P.; investigation, S.J., S.K., D.-G.Y., S.S.; validation, J.K., J.L., T.L.; resources, J.-H.W.; writing-original draft preparation, G.P. and T.L.; writing-review and editing, G.P. and T.L.; supervision, T.L.

Funding: This work was supported by a grant from the National Institute of Environment Research (NIER), founded by the Ministry of Environment (MOE) of the Republic of Korea (NIER-2017-03-02-048). Additional data analysis was supported by the Ministry of Environment (MOE) as "Climate Change Correspondence Program (project no.2016001300001)".

Acknowledgments: The authors thank the research scientists at the Transportation Pollution Research Center and the National Institute of Environmental Research (NIER) for their contributions to the success of the project.

Conflicts of Interest: The authors declare no conflict of interest.

\section{References}

1. Ministry of Environment (MOE). Enforcement Decree of the Clean Air Conservation; MOE: Yeongi-gun, Korea, 2017.

2. O'Driscoll, R.; Stettler, M.E.; Molden, N.; Oxley, T.; ApSimon, H.M. Real world $\mathrm{CO}_{2}$ and NOx emissions from 149 Euro 5 and 6 diesel, gasoline, and hybrid passenger cars. Sci. Total Environ. 2018, 621, 282-290.

3. Carslaw, D.C.; Rhys-Tyler, G. New insights from comprehensive on-road measurements of $\mathrm{NOx}_{2} \mathrm{NO}_{2}$ and $\mathrm{NH}_{3}$ from vehicle emission remote sensing in London, UK. Atmos. Environ. 2013, 81, 339-347. [CrossRef]

4. Carslaw, D.C.; Farren, N.J.; Vaughan, A.R.; Drysdale, W.S.; Young, S.; Lee, J.D. The diminishing importance of nitrogen dioxide emissions from road vehicle exhaust. Atmos. Environ. 2019, 1, 100002. [CrossRef]

5. Huang, Y.; Organ, B.; Zhou, J.L.; Surawski, N.C.; Hong, G.; Chan, E.F.; Yam, Y.S. Emission measurement of diesel vehicles in Hong Kong through on-road remote sensing: Performance review and identification of high-emitters. Environ. Pollut. 2018, 237, 133-142. [CrossRef] [PubMed] 
6. Huang, Y.; Organ, B.; Zhou, J.L.; Surawski, N.C.; Hong, G.; Chan, E.F.; Yam, Y.S. Remote sensing of on-road vehicle emissions: Mechanism, applications and a case study from Hong Kong. Atmos. Environ. 2018, 182, 58-74. [CrossRef]

7. Tkacik, D.S.; Lambe, A.T.; Jathar, S.; Li, X.; Presto, A.A.; Zhao, Y.; Blake, D.; Meinardi, S.; Jayne, J.T.; Croteau, P.L. Secondary organic aerosol formation from in-use motor vehicle emissions using a potential aerosol mass reactor. Environ. Sci. Technol. 2014, 48, 11235-11242. [CrossRef] [PubMed]

8. Link, M.F.; Kim, J.; Park, G.; Lee, T.; Park, T.; Babar, Z.B.; Sung, K.; Kim, P.; Kang, S.; Kim, J.S. Elevated production of $\mathrm{NH}_{4} \mathrm{NO}_{3}$ from the photochemical processing of vehicle exhaust: Implications for air quality in the Seoul Metropolitan Region. Atmos. Environ. 2017, 156, 95-101. [CrossRef]

9. Gordon, T.; Presto, A.; May, A.; Nguyen, N.; Lipsky, E.; Donahue, N.; Gutierrez, A.; Zhang, M.; Maddox, C.; Rieger, P. Secondary organic aerosol formation exceeds primary particulate matter emissions for light-duty gasoline vehicles. Atmos. Chem. Phys. 2014, 14, 4661-4678. [CrossRef]

10. Lee, J.T.; Son, J.; Kim, J.; Choi, Y.; Yoo, H.-M.; Kim, K.J.; Kim, J.S.; Park, S.W.; Park, G.; Park, T. Comparison of Chemical Composition of Particulate Matter Emitted from a Gasoline Direct Injected (GDI) Vehicle and a Port Fuel Injected (PFI) Vehicle using High Resolution Time of Flight Aerosol Mass Spectrometer (HR-ToF-AMS). Asian. J. Atmos. Environ. 2016, 10, 51-56. [CrossRef]

11. Wei, L.; Yao, C.; Wang, Q.; Pan, W.; Han, G. Combustion and emission characteristics of a turbocharged diesel engine using high premixed ratio of methanol and diesel fuel. Fuel 2015, 140, 156-163. [CrossRef]

12. Hasan, A.O.; Abu-Jrai, A.; Ala'a, H.; Tsolakis, A.; Xu, H. HC, CO and NOx emissions reduction efficiency of a prototype catalyst in gasoline bi-mode SI/HCCI engine. J. Environ. Chem. Eng. 2016, 4, 2410-2416. [CrossRef]

13. Meng, Z.; Lin, W.; Zhang, R.; Han, Z.; Jia, X. Summertime ambient ammonia and its effects on ammonium aerosol in urban Beijing, China. Sci. Total Environ. 2017, 579, 1521-1530. [CrossRef] [PubMed]

14. Tang, W.; Cai, Y.; Wang, J. Experimental studies on the diesel engine urea-SCR system using a double NOx sensor system. Environ. Eng. Res. 2015, 20, 397-402. [CrossRef]

15. Tan, P.-Q.; Hu, Z.-Y.; Lou, D.-M. Regulated and unregulated emissions from a light-duty diesel engine with different sulfur content fuels. Fuel 2009, 88, 1086-1091. [CrossRef]

16. Wang, T.; Quiros, D.C.; Thiruvengadam, A.; Pradhan, S.; Hu, S.; Huai, T.; Lee, E.S.; Zhu, Y. Total particle number emissions from modern diesel, natural gas, and hybrid heavy-duty vehicles during on-road operation. Environ. Sci. Technol. 2017, 51, 6990-6998. [CrossRef] [PubMed]

17. Maricq, M.M.; Szente, J.J.; Jahr, K. The impact of ethanol fuel blends on PM emissions from a light-duty GDI vehicle. Aerosol Sci. Technol. 2012, 46, 576-583. [CrossRef]

18. Borsari, V.; de Assunção, J.V. Ammonia emissions from a light-duty vehicle. Transp. Res. D Transp. Environ. 2017, 51, 53-61. [CrossRef]

19. Reşitoğlu, İ.A.; Altinişik, K.; Keskin, A. The pollutant emissions from diesel-engine vehicles and exhaust aftertreatment systems. Clean Technol. Environ. Policy 2015, 17, 15-27. [CrossRef]

20. Carslaw, D.C.; Murrells, T.P.; Andersson, J.; Keenan, M. Have vehicle emissions of primary $\mathrm{NO}_{2}$ peaked? Faraday Discuss. 2016, 189, 439-454. [CrossRef]

21. He, C.; Li, J.; Ma, Z.; Tan, J.; Zhao, L. High $\mathrm{NO}_{2} / \mathrm{NOx}$ emissions downstream of the catalytic diesel particulate filter: An influencing factor study. J. Environ. Sci. 2015, 35, 55-61. [CrossRef]

22. Ban-Weiss, G.A.; McLaughlin, J.P.; Harley, R.A.; Kean, A.J.; Grosjean, E.; Grosjean, D. Carbonyl and nitrogen dioxide emissions from gasoline-and diesel-powered motor vehicles. Environ. Sci. Technol. 2008, 42, 3944-3950. [CrossRef] [PubMed]

23. Shin, H.J.; Park, J.H.; Park, J.S.; Song, I.H.; Park, S.M.; Roh, S.A.; Son, J.S.; Hong, Y.D. The long term trends of tropospheric ozone in major regions in Korea. Asian. J. Atmos. Environ. 2017, 11, 235-253. [CrossRef]

(C) 2019 by the authors. Licensee MDPI, Basel, Switzerland. This article is an open access article distributed under the terms and conditions of the Creative Commons Attribution (CC BY) license (http://creativecommons.org/licenses/by/4.0/). 